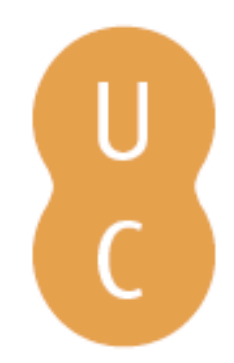

\title{
nommalina
}

\section{Caracterização geotécnica de zonas degradadas nas margens do rio Mondego em} Coimbra
Autor(es):
QuintaFerreira, M.; Oliveira, M. A.; Henriques, J.
Publicado por: Imprensa da Universidade de Coimbra
URL
persistente:
URI:http://hdl.handle.net/10316.2/31485
DOI:
DOI:http://dx.doi.org/10.14195/978-989-26-0531-9_41
Accessed : $\quad$ 26-Apr-2023 13:47:50

A navegação consulta e descarregamento dos títulos inseridos nas Bibliotecas Digitais UC Digitalis, UC Pombalina e UC Impactum, pressupõem a aceitação plena e sem reservas dos Termos e Condições de Uso destas Bibliotecas Digitais, disponíveis em https://digitalis.uc.pt/pt-pt/termos.

Conforme exposto nos referidos Termos e Condições de Uso, o descarregamento de títulos de acesso restrito requer uma licença válida de autorização devendo o utilizador aceder ao(s) documento(s) a partir de um endereço de IP da instituição detentora da supramencionada licença.

Ao utilizador é apenas permitido o descarregamento para uso pessoal, pelo que o emprego do(s) título(s) descarregado(s) para outro fim, designadamente comercial, carece de autorização do respetivo autor ou editor da obra.

Na medida em que todas as obras da UC Digitalis se encontram protegidas pelo Código do Direito de Autor e Direitos Conexos e demais legislação aplicável, toda a cópia, parcial ou total, deste documento, nos casos em que é legalmente admitida, deverá conter ou fazer-se acompanhar por este aviso.

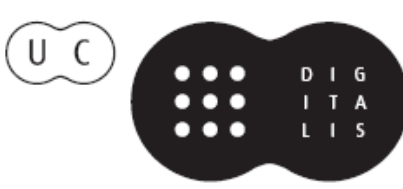



41

\section{CARACTERIZAÇÃO GEOTÉCNICA DE ZONAS DEGRADADAS NAS MARGENS DO RIO MONDEGO EM COIMBRA}

\section{GEOTECHNICAL CHARACTERIZATION OF DEGRADED RIVER BANKS IN THE MONDEGO RIVER IN COIMBRA}

M. Quinta-Ferreira ${ }^{1,2}$, M. A. Oliveira ${ }^{2} \& \mathrm{~J}_{\text {. }}$ Henriques $^{2}$

Resumo - Apresentam-se a metodologia e os trabalhos realizados no estudo e zonamento geotécnico de zonas degradadas nas margens do rio Mondego, entre o Parque Manuel Braga e o Açude-Ponte em Coimbra, Portugal. Após a identificação das zonas mais problemáticas, foi efetuado o reconhecimento geológico e realizadas quatro sondagens em complemento de outras onze, mais antigas. As margens são essencialmente constituídas por terrenos artificiais, que englobam pavimentos, tout-venant, aterros heterogéneos e blocos calcários com argamassa hidráulica, que constituem os muros de suporte existentes na margem do rio. Os terrenos naturais são aluviōes predominantemente arenosas com intercalaçôes de lodo argilo-siltoso, passando em profundidade a cascalheira, seixos e areia. Foram consideradas duas zonas geotécnicas nas aluviôes: uma constituída por areias e lodos, e a outra constituída por cascalheira. A cascalheira tende a apresentar melhores condiçóes de resistência e menor deformabilidade, embora os valores do ensaio SPT sejam muito variáveis. As deficiências observadas nos muros e diques terão sido originadas quer pela consolidação das aluvióes mais finas, quer pelos assentamentos e baixa resistência dos aterros soltos.

Palavras-chave - Margens do Mondego; Deformaçôes; Estudo geotécnico

Abstract - The methodology and the prospection works executed in the study and geotechnical zoning of degraded areas of the banks of the Mondego river, between the Manuel Braga Park and the Bridge-weir in Coimbra, Portugal are presented. After the definition of the most problematic areas, a geological reconnaissance and four boreholes were done, com-

\footnotetext{
${ }^{1}$ Departamento de Ciências da Terra, Centro de Geociências, Largo Marquês de Pombal, Universidade de Coimbra, 3000-272 Coimbra, Portugal; mqf@dct.uc.pt,

${ }^{2}$ Instituto Pedro Nunes, IPNlabgeo, Rua Pedro Nunes, 3030-199 Coimbra, Portugal; maoliveira@ipn.pt; jp.quintela@gmail.com
} 
plemented by other eleven boreholes already available. The banks are mainly constituted of artificial ground, including pavements, tout-venant, heterogeneous landfills and limestone blocks cemented with hydraulic mortar, belonging to the retaining walls of the riverbanks. The natural ground is predominantly sandy alluvium with interbedded silty-clay mud, changing in depth to gravel, pebbles and sand. Two geotechnical zones were considered in the alluvium: one constituted by sand and mud, and the other constituted by gravel. The alluvium of the lower zone tends to present higher strength, although the values of the SPT tests are quite variable. The deficiencies would be caused by the consolidation of the alluvium mud and by the settlement and low strength of the loose fills.

\section{Keywords - Mondego Banks; Deformations; Geotechnical Study.}

\section{1 - Introduçáo}

A existência de deficiências nos muros e diques de contenção, tais como fissuras sub-verticais e inclinaçáo excessiva, assentamentos nos muros, escadas e rampas, justificaram o estudo das características geotécnicas das margens do rio Mondego, na cidade de Coimbra (QUINTA-FERREIRA et al., 2011). Estas anomalias, detetadas ao longo dos últimos anos, têm sofrido agravamento, o que induziu a tomada de algumas medidas de segurança por parte do Município de Coimbra, nomeadamente a interdição do estacionamento junto ao rio, entre a estação da comboio de Coimbra-A e o Açude-Ponte.

O objetivo do presente estudo foi identificar e caracterizar as condiçôes geológicas e geotécnicas das zonas degradadas nas margens do rio Mondego, entre o Parque Manuel Braga e o Açude-Ponte, para seleçáo dos parâmetros geotécnicos a adotar no projeto de execução da estabilização das estruturas de contenção.

\section{2 - Metodologia de trabalho}

Tendo em vista os objetivos a concretizar foram executadas quatro sondagens à rotação com a realização de ensaios SPT - Standard Penetration Test (CIRIA, 1985) a cada $1,5 \mathrm{~m}$ de profundidade.

$\mathrm{Na}$ seleção dos locais de prospeção teve-se em consideração as necessidades específicas do projeto, nomeadamente a recolha dos elementos geotécnicos necessários à caracterização das zonas mais afetadas, e as condiçôes locais no que respeita à ausência de infraestruturas enterradas que pudessem ser danificadas com a realização das sondagens.

Foram ainda considerados os dados relativos a diversas sondagens realizadas no âmbito de outros projetos localizados na área em estudo, ou próximo dela:

- oito sondagens (S1 a S8) realizadas em março de 2009, para a empresa Águas do Mondego, S.A., no âmbito do projeto "Sistema Adutor da Boavista - Sector Central I - Traçado Comum com o Saneamento - Coimbra”, cedidas pela Câmara Municipal de Coimbra;

- três sondagens (S1 a S3) realizadas em março de 2010, pelo IPNlabgeo - Laboratório de Geotecnia do Instituto Pedro Nunes, no âmbito do projeto "Construção da Nova Escada de Peixes do Açude-Ponte de Coimbra". 
$\mathrm{Na}$ Figura 1 apresenta-se a localização das sondagens mencionadas, utilizando uma vista de satélite retirada do Google Earth.

\section{3 - Enquadramento geológico}

A área de estudo localiza-se na bacia hidrográfica do rio Mondego, no troço final da unidade hidromorfológica designada por Médio Mondego. A montante de Coimbra o rio percorre vales estreitos e encaixados que progressivamente se vão suavizando, começando o seu leito a alagar progressivamente para jusante da ponte da Portela, transitando definitivamente para um vale largo a partir do Açude-Ponte.

De acordo com a Carta Geológica de Portugal, na escala 1:50 000, Folha 19-D, Coimbra - Lousã (SOARES et al., 2007), encontram-se cartografados nas margens do rio Mondego depósitos aluvionares do Quaternário (Holocénico). Na margem direita afloram ainda os depósitos designados por Areias Vermelhas do Estádio, igualmente datados do Quaternário (Holocénico), sendo depósitos terrígenos que traduzem a evolução recente da geologia de superfície.

$\mathrm{O}$ vale aluvionar encaixa no firme rochoso constituído por calcários e arenitos pertencentes, respetivamente, às Camadas de Coimbra, do Jurássico Inferior (Sinemuriano Carixiano Inferior), e à Formação de Castelo Viegas, do Triásico Superior.

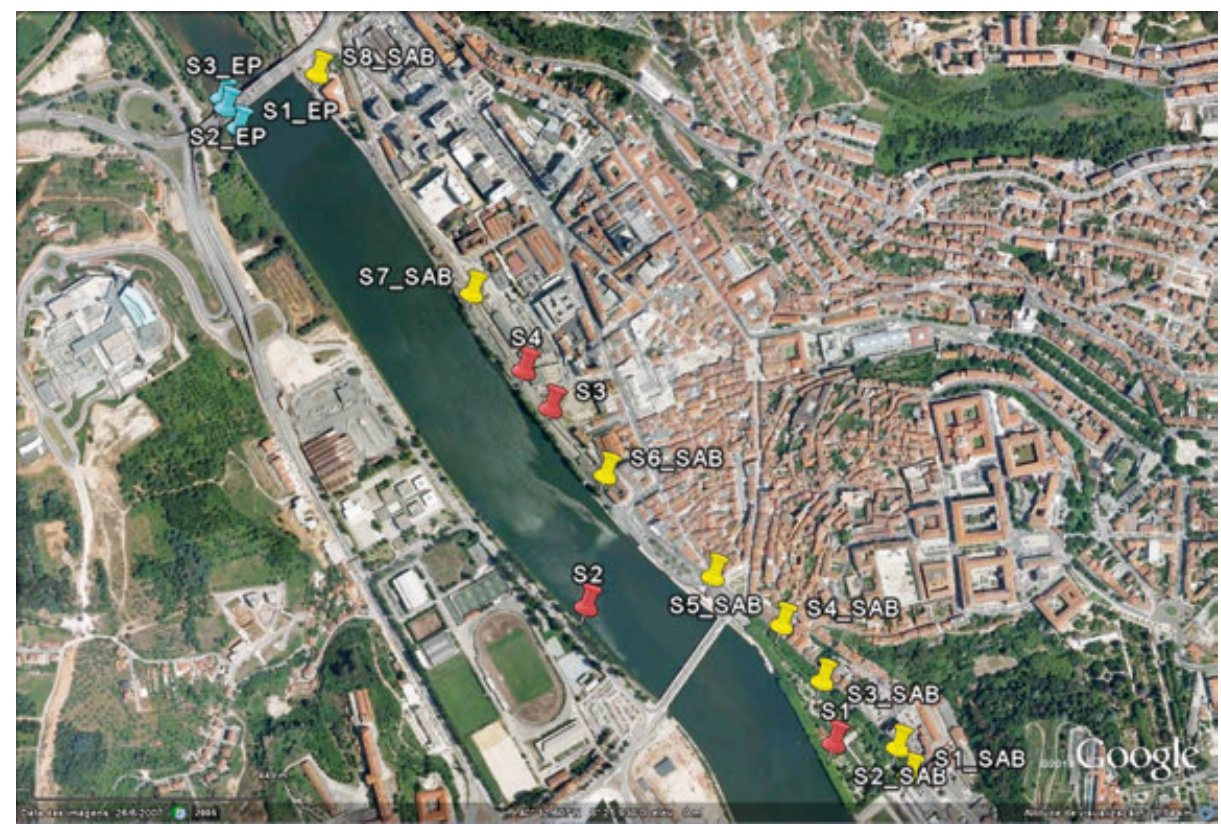

Fig. 1 - Localização das sondagens realizadas nas margens do rio Mondego, entre o Parque Manuel Braga e o Açude-Ponte, utilizando o Google Earth (2012). Sondagens: S1 a S4 (a vermelho) - sondagens realizadas no âmbito do presente estudo, em agosto de 2011; (S1_EP a S3_EP (a azul) - Escada de Peixe; S1_SAB a

S8_SAB (a amarelo) - Sistema Adutor da Boavista. 
As aluviōes resultam da acumulação de materiais associados à dinâmica fluvial, correspondendo a depósitos terrígenos com estruturação interna que traduzem a evolução do leito aluvial do rio Mondego.

A montante do Açude-Ponte, as aluvióes são constituídas por areias no topo e areias com seixos e calhaus na base, sendo as intercalaçóes lenticulares de lodos e argilas menos significativas, quer em espessura quer em extensão.

A espessura das aluvióes é variável, tendo sido determinado na zona da Quinta da Boavista, a montante da área a intervencionar, uma espessura de $25 \mathrm{~m}$ e na zona do Açude-Ponte uma espessura rondando os $40 \mathrm{~m}$.

As Camadas de Coimbra são essencialmente de natureza dolomítica, constituídas por dolomitos e calcários dolomíticos. A colina de Santa Clara, constituída pelos calcários das Camadas de Coimbra, encontra-se na margem esquerda do rio Mondego, enquanto na margem direita afloram calcários e arenitos.

A Formação de Castelo Viegas, uma das três maiores sequências do Grés de Silves, é constituída na base por terrenos de cor vermelha acastanhada, areno-conglomeráticos, sobre os quais assentam em descontinuidade corpos conglomeráticos, com calhaus de quartzito e de quartzo (SOARES et al., 1985, 2007).

Na Figura 2 apresenta-se um extrato da Carta Geológica de Portugal, na escala 1:50 000, Folha 19-D, Coimbra-Lousã, com o enquadramento geológico parcial da zona em estudo.

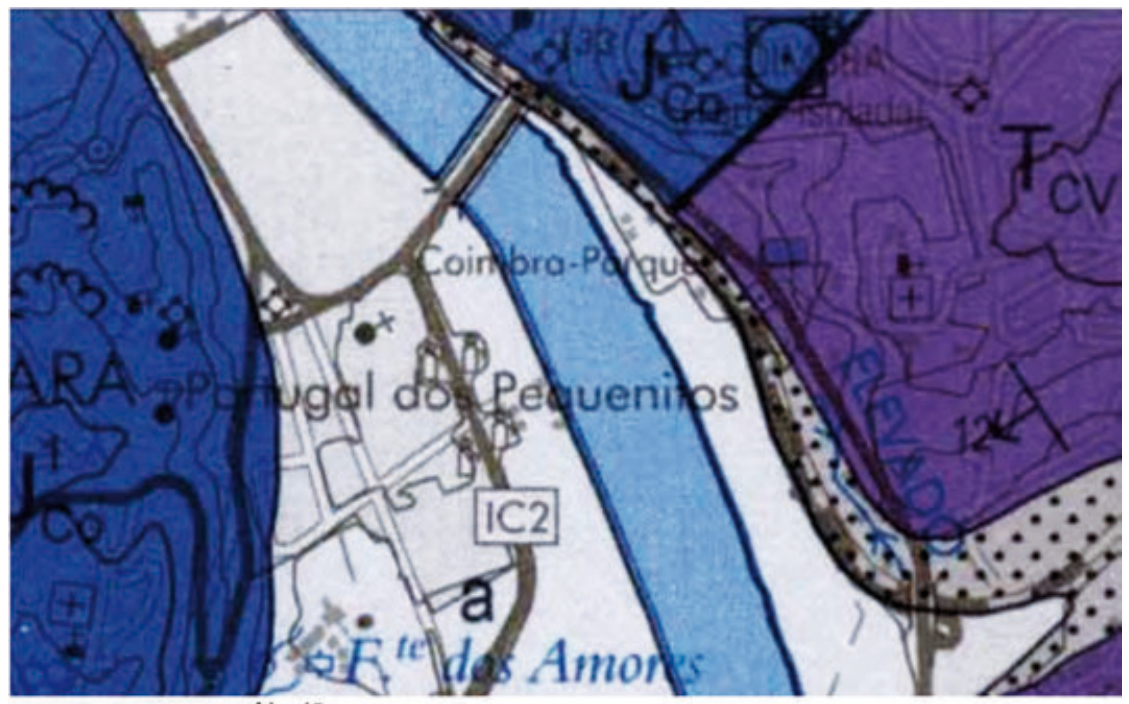

a - Aluviōes

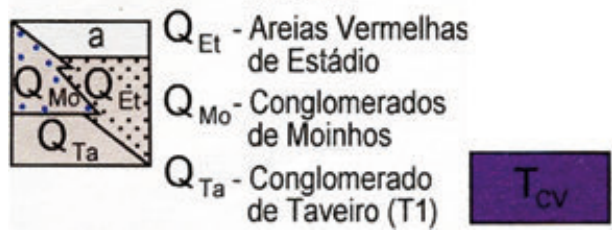

Formação de Castelo Viegas: conglomerados, arenitos e pelitos

Fig. 2 - Enquadramento geológico da zona: extrato da Carta Geológica de Portugal, na escala 1:50 000, Folha 19-D, Coimbra-Lousã (extraído de SOARES et al., 2007). 


\section{4 - Trabalhos de prospeção}

$\mathrm{Na}$ sequência da avaliação dos trabalhos de prospeção recentes, que foram coligidos sobre a zona em análise, foi decido realizar mais quatro sondagens, três na margem direita do rio Mondego, e uma na margem esquerda (Fig. 1). Todas as quatro sondagens foram realizadas com um equipamento APAFOR - 30D (Fig. 3), utilizando-se para a furação o caroteiro do tipo T2 de $76 \mathrm{~mm}$, com tubo de revestimento de $84 / 77 \mathrm{~mm}$ de diâmetro externo/interno respetivamente, de modo a garantir a estabilidade do furo e permitir a execução dos ensaios SPT.

Para as zonas de constituição rochosa foi contabilizada a percentagem de recuperação simples (IR), embora não tenham sido contabilizados os valores de RQD (Rock Quality Designation) pois que os materiais rochosos amostrados não se encontravam "in situ", por pertencerem às estruturas dos muros de contenção construídos nas margens do Mondego. Durante a execução dos trabalhos de prospeção houve o cuidado de tentar identificar vazios na base dos muros, no interior dos aterros ou dos aluvióes, que pudessem indicar possíveis subescavaçóes abaixo das fundaçóes dos muros, vazios por efeitos de arco e eventuais erosôes internas.

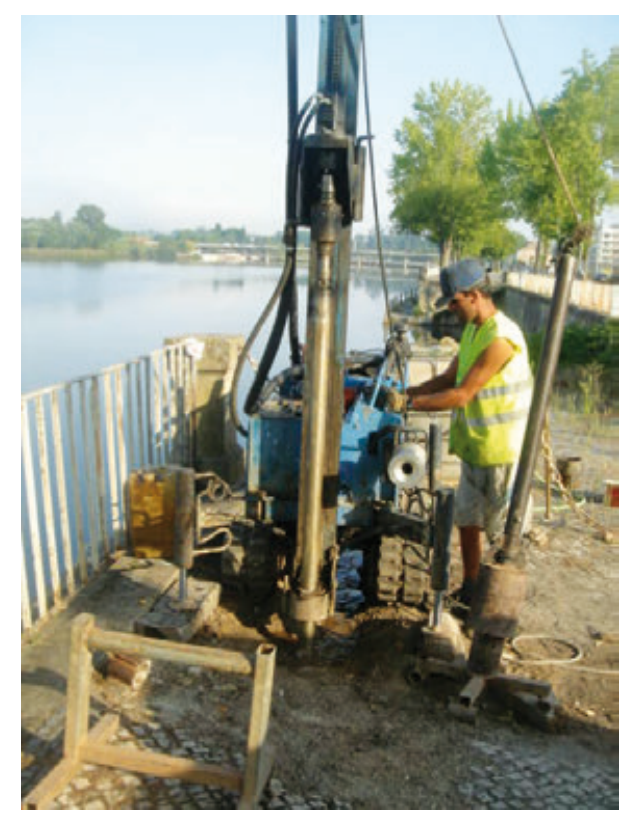

Fig. 3 - Equipamento utilizado na execução das sondagens, durante a realização da sondagem S4.

\section{5 - Interpretação e análise dos resultados}

Com base na informação disponível interpretou-se a distribuição e as características geológicas e geotécnicas dos terrenos em estudo e definiu-se o seu zonamento em profundidade (Figura 4), tendo sido consideradas as seguintes unidades geotécnicas: 

a) terrenos artificiais;
b) zona geotécnica 1 (ZG1) - Aluvióes (areias e lodos);
c) zona geotécnica 2 (ZG2) - Aluviōes (cascalheira).

A zona definida como "terrenos artificiais" é muito heterogénea na constituição, englobando desde os pavimentos, o tout-venant e o coroamento dos aterros, os aterros heterogéneos e ainda os blocos calcários com argamassa hidráulica, que constituem os muros de suporte construídos na margem do rio. Os terrenos artificiais apresentam uma espessura de cerca de 3,5m junto ao Açude-Ponte, atingindo um máximo na zona entre as sondagens S3 e S4, onde a base da unidade se encontra a cerca de 6,5 m de profundidade. No Parque Manuel Braga, no local de realização da sondagem S1, a unidade de terrenos artificiais atinge os 5,0 $\mathrm{m}$ de espessura e na margem esquerda do rio Mondego, a norte da ponte de Santa Clara, apresenta 4,0 m (sondagem S2). A camada superficial de pavimentos, tout-venant e coroamento de pavimentos, com espessura a variar entre os $0,2 \mathrm{~m}$ e os $0,7 \mathrm{~m}$, foi intersectada nas sondagens S2 e S5_SAB a S7_SAB. Os blocos de calcário com argamassa hidráulica, que constituem os muros de suporte construídos na margem do rio, foram detetados nas sondagens S3 e S4. A camada de aterro é heterogénea, constituída genericamente por areias de granulometria extensa, por vezes de natureza areno-siltosa ou argilosa, com fragmentos rochosos e, em alguns locais, resíduos de construção (entulho). Trata-se de uma aterro mal compactado, com baixa resistência, com valores de SPT entre 2 e 9 pancadas.

Em algumas das sondagens realizadas na margem direita do rio foram detetados restos de madeira pertencentes às estruturas de estacas utilizadas no reforço da fundação dos muros de suporte das margens do rio, quando da sua construção. A profundidade a que foram encontrados varia, entre os $6,5 \mathrm{~m}$ e os $7,5 \mathrm{~m}$, correspondendo localmente à transição entre os terrenos artificiais e as aluvióes subjacentes.

Por baixo dos terrenos artificiais encontra-se a zona geotécnica 1 (ZG1) constituída por depósitos aluvionares, de natureza essencialmente arenosa e lodosa, que ocorrem até uma profundidade que varia entre os $9,5 \mathrm{~m}$ e os $15,0 \mathrm{~m}$. Os valores de SPT obtidos variam em geral entre as 5 e as 11 pancadas, indicando a presença de solos pouco compactos. Nesta zona geotécnica há ainda a ter em consideração que os níveis lodosos surgem intercalados nas areias, e que os níveis lodosos são os menos resistentes e os mais compressíveis.

Considera-se como zona geotécnica 2 (ZG2) as aluviōes constituídas por cascalheira, seixos e areia de granulometria média a grosseira, que se encontram a maior profundidade. Esta zona foi detetada apenas nas sondagens realizadas no âmbito deste estudo, em agosto de 2011, e que foram mais profundas. Assim, na margem direita do rio, encontra-se a ZG2 a partir dos $14,0 \mathrm{~m}$ ou 15,0 m de profundidade. Na margem esquerda esta zona foi identificada a partir dos $9,5 \mathrm{~m}$ de profundidade. As aluvióes da ZG2 (cascalheira) tendem a apresentar melhores características de resistência, embora os valores do ensaio SPT sejam muito variáveis, de 7 a 60 pancadas.

Os parâmetros geotécnicos considerados adequados para as unidades anteriormente descritas são apresentados na Tabela 1 , tendo sido estimados em função dos valores de $\mathrm{N}$ obtidos nos ensaios SPT e nas litologias atravessadas com base na experiência dos autores, em valores tabelados e em correlaçôes propostas na bibliografia da especialidade (LOOK, 2007; VALLEJO, 2004). 
Tabela 1 - Síntese dos parâmetros geotécnicos.

\begin{tabular}{|c|c|c|c|c|c|}
\hline \multirow[b]{2}{*}{ Unidade } & \multirow[b]{2}{*}{ Designação } & \multicolumn{4}{|c|}{ Parâmetros Geotécnicos } \\
\hline & & $\begin{array}{c}\text { SPT } \\
\text { (node panc.) }\end{array}$ & $\begin{array}{l}\text { Ângulo de atrito } \\
\text { interno }(\phi)\end{array}$ & $\begin{array}{l}\text { Coesáo } \\
\text { (c) }\end{array}$ & $\begin{array}{l}\text { Peso específico } \\
\qquad\left(\mathrm{kN} / \mathrm{m}^{3}\right)\end{array}$ \\
\hline \multirow{3}{*}{$\begin{array}{l}\text { Terrenos } \\
\text { Artificiais }\end{array}$} & $\begin{array}{l}\text { Pavimento, tout-venant e } \\
\text { coroamento de pavimentos }\end{array}$ & ---- & ---- & ---- & ---- \\
\hline & $\begin{array}{l}\text { Blocos calcários com } \\
\text { argamassa hidráulica }\end{array}$ & 60 & ---- & -..- & --- \\
\hline & Aterro heterogéneo & $2-9$ & $29-30$ & 0 & $<18$ \\
\hline ZG1 & Aluviōes - areias e lodos & $5-11$ & $29-30$ & 0 & $16-18$ \\
\hline ZG2 & Aluviōes - cascalheira & $\begin{array}{c}7-39 \\
56-60\end{array}$ & $30-38$ & $\begin{array}{c}0 \\
----\end{array}$ & $\begin{array}{c}18-20 \\
---\end{array}$ \\
\hline
\end{tabular}

\section{6 - Consideraçôes finais}

Os dados obtidos com base no estudo geológico e na realização dos trabalhos de prospeção e ensaio permitiram elaborar diversos perfis geológico-geotécnicos interpretativos de que se apresenta um exemplo na Figura 4, sendo indicada a distribuiçáo das unidades geotécnicas consideradas. $\mathrm{O}$ zonamento geotécnico constitui uma síntese e interpretação dos dados recolhidos durante o estudo, podendo no entanto ocorrer variaçôes que não foram detetadas.

Embora a zona em estudo das margens do Mondego, entre o Parque Manuel Braga e o Açude-Ponte, seja extensa e a distância entre os pontos de prospeção considerável, foi possível elaborar o modelo geológico-geotécnico, verificando-se genericamente a existência de duas zonas distintas, uma constituída por terrenos artificiais e outra de aluvião, em ambas as margens do rio.

Os terrenos artificiais englobam pavimentos, tout-venant e coroamento de pavimentos, aterros heterogéneos e blocos calcários com argamassa hidráulica, que constituem os muros de suporte construídos nas margens do rio Mondego.

As aluvióes mais superficiais são de composição predominantemente arenosa, possuindo intercalaçôes de lodo argilo-siltoso. Em profundidade passam a apresentar granulometria mais grosseira, essencialmente cascalheira, seixos e areia. Esta variaçáo justificou a consideração de duas zonas geotécnicas no terreno natural: a zona geotécnica 1 (ZG1), designada por aluvióes - areias e lodos, e a zona geotécnica 2 (ZG2), designada por aluviôes - cascalheira.

As aluviôes da ZG2 tendem a apresentar melhores condições de resistência, mas com os valores do ensaio SPT muito variáveis.

O nível freático, medido após a conclusão das sondagens, foi detetado entre os 1,6m e os 4,0m de profundidade, correspondendo genericamente ao nível da água na albufeira do Açude.

Quanto às causas para os danos observados, vários fatores terão contribuído. As sobrecargas nas aluviôes, provocadas pelos terrenos artificiais, que chegam a ter mais de $6 \mathrm{~m}$ de altura, provocaram a consolidação dos solos finos intercalados nas aluviōes, originando assentamentos que se foram agravando no tempo. A deformação das fundaçôes dos 
muros das margens do Mondego e o impulso dos aterros no tardoz, facilitaram o seu basculamento com a abertura de fendas em diversos locais.

Por outro lado a deformação dos próprios aterros soltos, com valores de SPT entre 2 e 9, permitiram a ocorrência de assentamentos, danificando pavimentos e passeios nas zonas adjacentes aos muros de alvenaria com um comportamento mais rígido.

Para se entender a evolução e comportamento das deformaçôes no tempo, foram colocadas marcas superficiais nos muros e diques que apresentam maiores danos.

Agradecimentos - Este trabalho foi financiado pelo Estado Português através da FCT - Fundação para a Ciência e a Tecnologia no âmbito do projecto PEst-OE/CTE/ UI0073/2011 do Centro de Geociências.

\section{7 - Referências Bibliográficas}

GOOGLE EARTH ( 2012) - Google.

LOOK, B. (2007) - Handbook of Geotechnical Investigation and Design Tables. Taylor \& Francis/Balkema. Taylor \& Francis Group, London, UK.

VALLEJO, L. I. G. (2004) - Ingeniería Geológica. Pearson Educácion, S.A. (Madrid).

QUINTA-FERREIRA, M., OLIVEIRA, M. A., PERES e SÁ, M. \& HENRIQUES, J. (2011) - Estudo da Estabilidade das Margens do Mondego, entre o Parque Manuel Braga e o Açude-Ponte. Coimbra. Estudo Geológico-Geotécnico. Relatório IPN/LABGEO/2011/0055-R(1.0). Trabalho solicitado pela Câmara Municipal de Coimbra.

CIRIA (1985) - The Standard Penetration Test (SPT): Methods and Use. REPORT 143. CIRIA (Construction Industry Research and Information Association).

SOARES, A. F., et al. (2007) - Carta Geológica de Portugal, na escala 1/50 000. Notícia Explicativa da Folha 19-D, Coimbra-Lousã. INETI, Departamento de Geologia, Lisboa.

SOARES, A. F., MARQUES, J. F. \& ROCHA, R. B. (1985) - Contribuição para o conhecimento geológico de Coimbra. Memórias e Notícias no. 100, Publicação do Museu e Laboratório Mineralógico e Geológico da Universidade de Coimbra. 


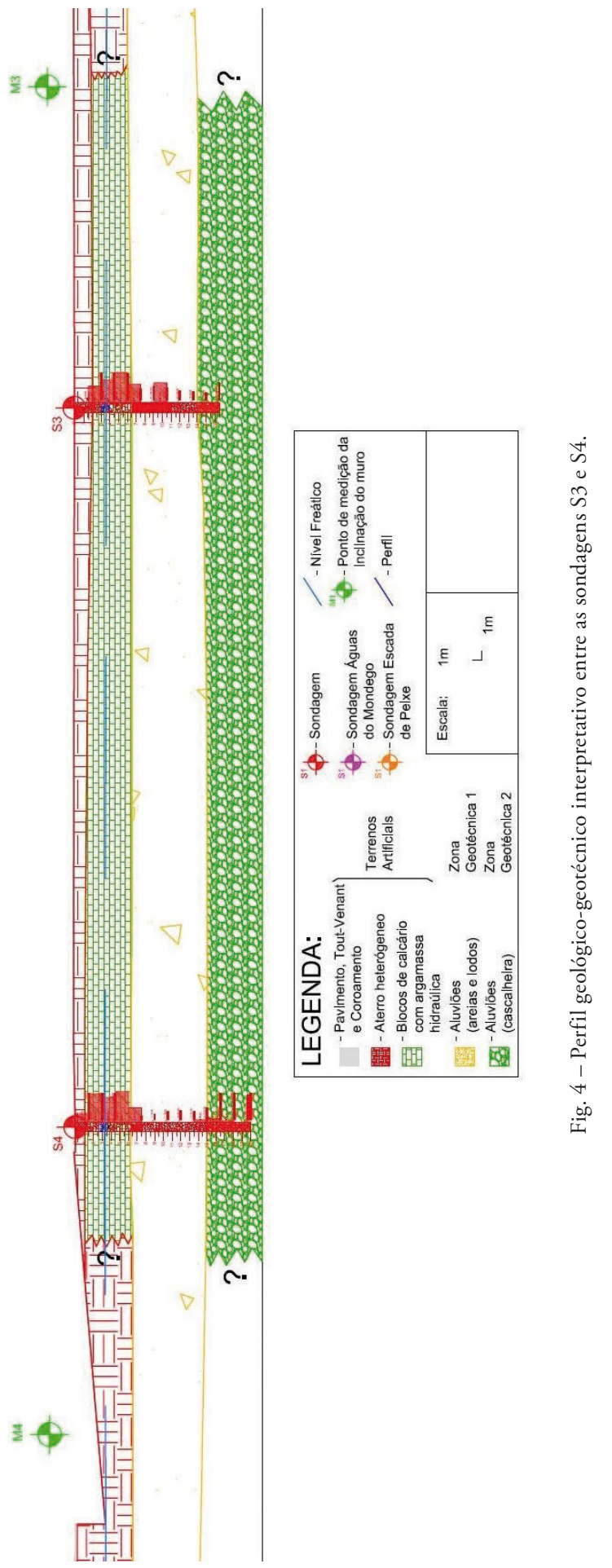

